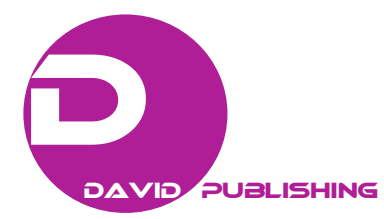

\title{
Global Aspects of Flood Risk Management
}

\author{
Wolfgang Kron \\ Geo Risks Research, Munich Reinsurance Company, 80802 Munich, Germany
}

\begin{abstract}
Various flood disasters in the last decade have confirmed that the risk from flooding has been increasing significantly worldwide. The driving factors for the risk are the unabated increase in global population, the concentration of people in high-risk areas such as coasts and flood plains, the rise in vulnerability of assets, infrastructure and social systems, and the consequences of climate change. Risk reduction is based on comprehensive risk management from identification of the hazard and assessing the risk to building defenses. To achieve this, general awareness at all levels in a society is key. It is not sufficient merely to be aware of the situation-findings must be acted upon with no significant delay. Flood-related computations have progressed considerably in recent years, but model results can only be as good as their input data. Modeling floods and flood losses is very complex, as model parameters are subject to change during an event and conditions sometimes greatly depend on small-scale factors.
\end{abstract}

Key words: Flood disasters, flood risk, risk reduction, risk management, insurance.

\section{Introduction}

Water is responsible for most natural disaster losses in the world. Every year, various regions suffer from flood disasters resulting from rainfall or snowmelt, storm surges or tsunamis. 2013 in particular was a year with some exceptional floods. The most severe in terms of loss of life and property occurred in the Philippines (storm surge during Typhoon Haiyan), Central Europe and Uttarakhand/India, but there were also significant, and for the area concerned disastrous, events in Colorado (USA), Canada, Mexico, Indonesia, Australia and Southern Africa (South Africa/Mozambique/Zimbabwe). The first half of 2014 saw devastating floods in some Balkan countries, in Italy and in the Malaysia-Thailand border region.

Tables 1 and 2 show the costliest flood disasters (> US\$ 5 bn overall loss) and those with the highest death tolls $(>1,000)$ since the beginning of the century (excluding tsunamis). Disasters with high financial losses mainly occur in well developed countries, whereas high numbers of fatalities mostly result from events in poor regions where, though natural disasters do not often produce very high losses in monetary

Corresponding author: Wolfgang Kron, Dr., main research field: flood risk. E-mail: wkron@munichre.com. terms, they may still be severe and momentous for the country affected.

Table 1 also reveals that the insured portion for the costliest events is much higher in developed than in poor countries. The insurance industry can assume a considerable share of the costs (and therefore also the risk), thus relieving the burden on a nation's budget and economy. Disasters usually affect poor countries much more severely than rich countries [1].

Natural disasters can assume very different forms: in terms of the area affected (regional intensity or large-scale impact), high number of fatalities, huge monetary losses and severe impact on the local economy. Many disasters happen on coasts. Due to the concentration of people and assets, they are certainly the high-risk areas of the world-and home to a third of the world's population [2].

There is no doubt that natural disasters, especially weather-related events, have been increasing dramatically in frequency and intensity. While there were only three flood events with overall losses of more than US\$2 bn (in original values; US\$ $2 b n$ in 1980 translates roughly to US\$ 5.8bn in 2014 after adjustment for inflation) before 1990, the last decade of the 20th century saw six events in which losses exceeded 
Table 1 Floods (excluding tsunamis) in the period 2000-2014 in which material losses of US\$ 5bn and more (original values) occurred. Source: Munich Re NatCatSERVICE 2015.

\begin{tabular}{|c|c|c|c|c|c|}
\hline Year & Country/region & Event/basin(s)/area & $\begin{array}{l}\text { Overall losses due } \\
\text { to water (US\$ bn) }\end{array}$ & $\begin{array}{l}\text { Insured losses due } \\
\text { to water (US\$ bn) }\end{array}$ & $\%$ insured (-) \\
\hline 2005 & USA & Hurricane Katrina (Gulf Coast) & $83^{(2 / 3)}$ & $41.5^{(2 / 3)}$ & 50 \\
\hline 2012 & USA, Canada, Caribbean & Hurricane Sandy (Northeast) & $46^{(2 / 3)}$ & $19.7^{(2 / 3)}$ & 43 \\
\hline 2011 & Thailand & Chao Phraya & 43 & 16 & 37 \\
\hline 2002 & Central, Southern Europe & Elbe, Danube; Italy & 16.5 & 3.4 & 21 \\
\hline 2008 & Caribbean, USA & Hurricane Ike & $13^{(1 / 3)}$ & $6^{(1 / 3)}$ & 46 \\
\hline 2013 & Central Europe & Danube, Elbe & 12.6 & 3.1 & 25 \\
\hline 2008 & USA & Midwest; Missouri & 10 & 0.5 & 5 \\
\hline 2010 & Pakistan & Indus & 9.5 & 0.1 & 1 \\
\hline 2000 & Italy, Switzerland & Southern Alps & 8.5 & 0.48 & 6 \\
\hline 2010 & China & East, Southeast, South & 8 & 0.15 & 2 \\
\hline 2012 & China & East, Northeast, Southeast & 8 & 0.18 & 2 \\
\hline 2004 & Caribbean, USA & Hurricane Ivan & $8^{(1 / 3)}$ & $5^{(1 / 3)}$ & 60 \\
\hline 2003 & China & Center, South, East, Northwest & 7.9 & --- & -- \\
\hline 2004 & China & Southwest, Center, Northwest & 7.8 & --- & -- \\
\hline 2005 & Caribbean, Mexico, USA & Hurricane Wilma & $7^{(1 / 3)}$ & $4^{(1 / 3)}$ & 57 \\
\hline 2007 & China & South, Southwest, East, Center & 6.8 & --- & -- \\
\hline 2001 & USA & Tropical storm Allison (Houston) & 6 & 3.6 & 60 \\
\hline 2013 & Canada & West (Calgary) & 5.7 & 1.63 & 29 \\
\hline 2004 & Bangladesh, India, Nepal & Monsoon rains & 5 & --- & -- \\
\hline 2005 & India & Monsoon flash flood (Mumbai) & 5 & 0.77 & 15 \\
\hline 2011 & USA & Hurricane Irene (Northeast) & $5^{(1 / 2)}$ & $3^{(1 / 2)}$ & 55 \\
\hline 2013 & Philippines & Typhoon Haiyan & $5^{(1 / 2)}$ & $0.35^{(1 / 2)}$ & 7 \\
\hline
\end{tabular}

(1/4)/(1/3)/(1/2)/(2/3) The loss figure shows the-roughly estimated-losses attributed to flood (one quarter/one third/half/two thirds of the overall/insured losses); the remainder is attributed to windstorm. Example: the overall loss of Typhoon Haiyan (2013, Philippines) was US $\$ 10 \mathrm{bn}, 1 / 2$ of it (US\$ 5bn) was due to water.

Table 2 Floods (excluding tsunamis) in the period 2000-2014 in which more than 1,000 people died. Source: Munich Re NatCatSERVICE 2015.

\begin{tabular}{llll}
\hline Year & Region & Event & Deaths* \\
\hline 2008 & Myanmar & Cyclone Nargis & 140,000 \\
2013 & Philippines & Typhoon Haiyan & 6,334 \\
2013 & India & Flash floods & 5,500 \\
2007 & Bangladesh & Cyclone Sidr & 3,295 \\
2004 & India, Bangladesh, Nepal & Floods & 2,200 \\
2007 & Bangladesh, India, Nepal & Floods & 2,030 \\
2004 & Haiti, Dominican Republic & Floods & 2,000 \\
2004 & Haiti & Hurricane Jeanne & 2,000 \\
2010 & Pakistan & Floods & 1,760 \\
2010 & China & Floods & 1,467 \\
2000 & India & Floods & 1,430 \\
2003 & Bangladesh, India, Nepal, Pakistan & Floods, landslides & 1,400 \\
2005 & USA & Hurricane Katrina & 1,322 \\
2002 & Nepal, Bangladesh, India & Floods, mudslides & 1,300 \\
2011 & Philippines & Tropical storm Washi & 1,268 \\
2005 & India & Floods & 1,150 \\
2012 & Philippines & Typhoon Bopha & 1,067 \\
\hline
\end{tabular}

* Excluding those missing, but including fatalities from causes other than water in the event (e.g. landslide, wind, etc.). 


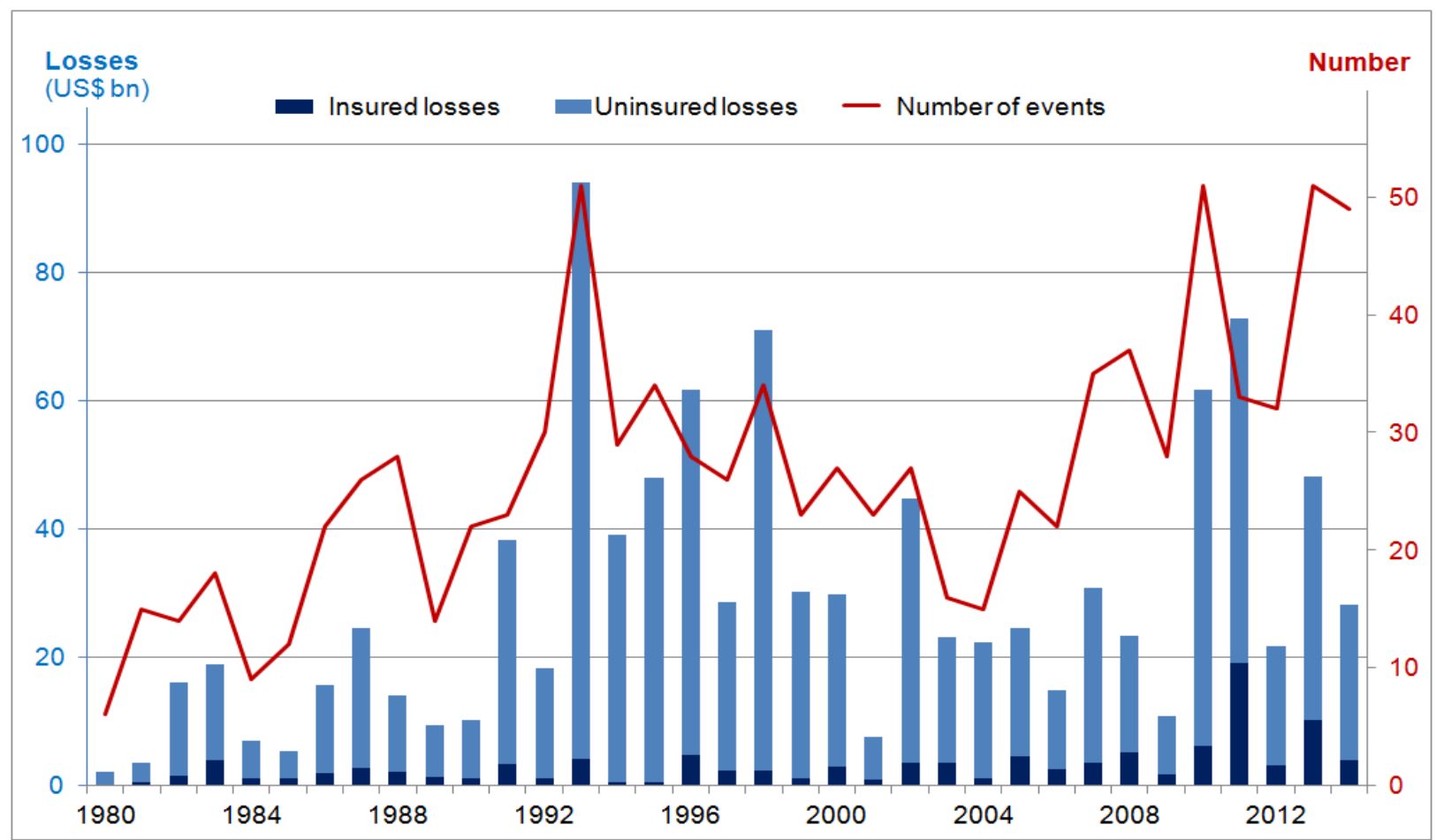

Fig. 1 Inflation-adjusted (to 2014 values) overall and insured annual flood losses (bars) and number of flood events (jagged line) per year from 1980 to 2014, derived from all events with losses exceeding US\$ 50m (in values of 2014). Only floods that are not associated with named tropical cyclones are included in the analysis. Source: Munich Re NatCatSERVICE 2015.

US\$ $10 \mathrm{bn}$ (and 13 events $\geq$ US $\$ 5 \mathrm{bn}$ ). The 2000 s were "quieter" (three events $\geq$ US\$ $10 \mathrm{bn}$ and ten events $\geq$ US\$ 5bn), but in the first third of the current decade we have already recorded three events $\geq$ US\$ $10 \mathrm{bn}$ and nine events $\geq$ US $\$ 5 \mathrm{bn}$. The increase in flood disasters is also confirmed if we consider not only the costliest but all significant floods. Fig. 1 shows the annual number of events with individual losses exceeding US\$ 50m (in inflation-adjusted values to make years comparable) and the associated overall and insured losses. All three quantities indicate an upward trend. Smaller events do not significantly influence this picture.

Recent large events have shown that financial losses resulting from physical damage are no longer the only significant ones. Indirect losses such as business interruption (bi), contingent business interruption (cbi) or the loss of market share a company suffers due to being out of business for a while have assumed new dimensions. These losses are not limited to the area directly affected by disaster, but may occur anywhere in the world, even far away from the location of a flood. For instance, the floods in Thailand in 2011 caused a globally felt shortage of hard disk drives, as a quarter of hard disk drives produced worldwide are manufactured there [3].

\section{Types of Flood}

Strictly speaking, flood is a secondary hazard. The generating phenomena (often not hazards themselves) are high or intense rainfall, high temperature (snowmelt) or low temperature (ice jam), earthquake (tsunami), or technical failure (breaching of a dam or embankment). There are three main types of flood event caused by hydro-meteorological factors: river flood, flash flood and storm surge. Other causes are lake flooding, groundwater flooding and water logging, dam break and glacier lake outburst flood, back-up flood, seiche, etc. Most tsunamis are generated by geophysical phenomena.

\subsection{River Flood}


The 2013 flood in Central Europe was a typical river flood. River floods (or basin-wide floods) are the result of copious rainfall (or snowmelt) continuing for a period of days or weeks over a large area during which the basin's (soil's) retention capacity is depleted. The drainage system of a catchment area conveys the rainwater directly to the main river(s). This type of flood does not occur suddenly. A flood wave is built up gradually, though sometimes in a relatively short period. As it propagates downstream, it can affect many reaches along the course of the river. The affected area may cover entire river basins and thousands of square kilometers. Water levels often remain high for a long time and interfere with the lives of people, not only by damaging property but also by preventing them from living their normal lives. In river floods, inundation always emanates from the river channel. The sequence of affected areas is therefore always the same, and zones with a different hazard (as regards flood frequency, but sometimes also flood intensity) can be identified.

\subsection{Flash Flood}

Flash floods (or off-plain floods) can happen practically anywhere. These floods are produced by intense rainfall, usually of short duration. They often occur over a very small area in conjunction with thunderstorms or over a large area during tropical storms. Flash floods have a sudden onset and last from a few hours to perhaps a day or two. This surprise effect is the reason why flash floods pose such a danger for people and are responsible for many lives lost each year. In sloped terrain, the water flows at high speed and has an incredible potential for destruction, whereas in flat areas the water cannot flow off fast enough due to the lack of a sufficient gradient and accumulates on the surface or in depressions. Sometimes flash floods mark the beginning of a major river flood, but often they are separate, individual events of only local significance, scattered randomly in space and time. Flows in affected watercourses grow rapidly and flood waves can gush downhill in next to no time and forge into areas where it may not even have rained at all. Mechanical forces, erosive capacity and transport of solids are critical factors associated with this type of flood.

\subsection{Storm Surge}

Storm surges can occur on the coast and along the shores of large lakes. Since they are created by wind, they are of meteorological rather than hydrological origin. They have extremely high loss potentials and have caused hundreds of thousands of fatalities, even in the recent past. In Bangladesh, death tolls of 300,000 and 140,000 were reported in 1970 and 1991 respectively, and 140,000 died in Myanmar during cyclone Nargis in 2008. Typhoon Haiyan claimed more than 6,000 lives in the Philippines in November 2013. In the past decade, storm surges induced by hurricanes Katrina (2005), Ike (2008) and Sandy (2012) have caused huge physical damage in North America.

\section{Computing the Flood Risk}

Hardly any other natural hazard has been as much in focus in recent years as floods. Great improvements have been made in describing their generation processes and conditions. In particular, weather forecasts have become much more precise and reliable, mostly based on satellite observations that define the initial stage of modeling (i.e. the state of the atmosphere) and the ability to handle and process incredible amounts of data in a short time thanks to the power of computers and storage devices (by using mathematical model equations).

However, the comprehensive modeling of a flood, and even more so, of flooding (i.e. the inundation caused by a high discharge), is very complex when it gets down to the individual property level, inundation depths and flow velocities. Computing the transformation of "available" rain or snowmelt water into runoff and discharge into a river involves many aspects: surface properties (slopes, catchment size, 
ground cover and topography, prescribed flow paths, etc.), underground properties (soil type, soil moisture, groundwater conditions, etc.) and the temporal (hyetograph) and spatial (moving speed and track) characteristics of the input quantity (e.g. rainfall). And these parameters only influence the amount of water that flows down a river. Flooding (inundation) is influenced by other parameters: the discharge capacity of the regular channel (cross-section, slope) and the floodplain/valley (width and shape of flood plain, existence of levees); possible/preferred flow paths and obstructions to the flow; the shape of the flood wave itself (very high and short, or moderately high and long).

Nowadays, flow paths, inundation depths and velocities can theoretically be calculated in detail and with a high degree of precision. High-resolution digital surface models and high-performance computer models and computers allow almost any given accuracy specification for a given flow situation. However, some users forget that a model can only produce correct and accurate results if all model parameters describe the reality appropriately. High resolution and high performance specifications are required for every model component. For instance, when using the exact altitude of a one square meter plot, we also need to know, for instance, the true roughness of this area and its infiltration parameters. However, who can specify these properties accurately and reliably, and with a reasonable amount of effort? Another example: a $30 \mathrm{~cm}$-high brick wall may well prevent a large area from flooding in reality, but not necessarily in the model if this micro-feature is not accounted for. Details and small-scale factors are very important in flood calculations.

Non-linear and therefore potentially highly influential effects are even aggravated in the case of damage assessment and loss estimation. Literally a few centimeters can often determine whether there is a large local loss or nothing happens. Fortunately, the "law of large numbers" usually comes into play here.
Rather than exact design values, statistical considerations become important, in particular for insurance purposes. The category of model that interests insurance companies most is flood loss estimation models for whole events, i.e. those that cover a large region (Probable Maximum Loss models). They do not deliver best estimates of individual losses and then produce a sum total, but assess the overall loss by means of statistical parameters and distribution functions, albeit based on physical computations. These physics may be more or less sophisticated, depending on the type of model, but the models can never become deterministic because they always rely on stochastic input too. If such models are applied to local problems, they may lead to wrong conclusions. Unfortunately, when a model is marketed, this is sometimes forgotten or concealed.

Extreme floods do not happen in a stationary environment. Therefore, many boundary conditions are not known beforehand, simply because it is the flowing water that creates them. During an event, erosion and sedimentation occur, and meanders are cut off, levees breached and bridges clogged up, etc., and new, often unforeseeable pathway systems are created. Hence, the flow field may change permanently during a flood situation.

The purpose of flood defense activities is to influence the paths the water is going to take. Sandbags and other artificial obstacles-which were not present at the outset and therefore not included in the model design-may completely change the modeled flow direction. This interaction of a flood with the boundary conditions is unique. Windstorms, hailstorms or earthquakes are not influenced by the features of the environment they afflict. But it is exactly this aspect that enables us to react to and influence flooding at all.

Finally, we must never forget that the input that drives our model (e.g. the 100-year rainfall event) is a statistical quantity with considerable and inherent uncertainty, which a) we cannot reduce to below a certain level and b) may be additionally subject to 
change due to changes in climate.

\section{From Hazard to Risk}

It is important to understand the circumstances under which flood disasters happen. Nature alone does not produce disasters, but only extreme events. A natural disaster happens if people and/or their possessions are affected so severely that a society's life is disrupted [4]. A well-prepared society is not likely to experience a disaster as easily as one that lacks many aspects of preparedness, from education and knowledge to building codes, and from functioning governance to availability of financial means. Disasters are hence not only products of chance but also the outcome of interaction between political, financial, social, technical and natural circumstances.

Similarly, the term "risk" should be defined and understood in an unambiguous and consistent way. In the scientific community, it is widely agreed that risk is the product of a hazard and its consequences [5]. Where there are no people or values that can be affected by a natural phenomenon, there is no risk. An extreme flood in an uninhabited region with no human property cannot result in disaster, so there is no risk associated with it. Similarly, a major flood in a well-prepared region will not become catastrophic. In a poorly prepared region, however, even a moderate event may cause a devastating disaster. The flood hazard is clearly highest in the first case, while the flood risk is highest in the third case. Hence, three components determine the risk [6]:

(a)The likelihood that a natural event may occur (hazard)

(b)The presence of people/property (exposure)

(c)Their vulnerability

Where there are no people or values that can be affected by a natural phenomenon, there is no risk. In a simplified but widely used way, risk can be defined as:

Risk $=$ Hazard $\cdot$ Exposure $\cdot$ Vulnerability

Hazard is the threatening natural event and its probability of occurrence; the exposure or the values at risk are the buildings/objects/humans/habitats/natural features that are present at the location involved; and vulnerability denotes the lack of resistance to damaging/destructive forces. Vulnerability can refer to human health and wellbeing (human vulnerability), structural integrity (physical vulnerability) or personal wealth (financial vulnerability). Insurance's contribution to risk control addresses the last of these factors. Values at risk and vulnerability are sometimes combined to form consequences. Thus, risk can also be written as

\section{Risk $=$ Hazard $\cdot$ Consequences.}

The overall risk is determined by computing the integral over all possible threatening events (intensities and frequencies) and their respective consequences (associated losses). Hence, risk is identical to the (expected) average annual loss if the hazard is specified in terms of exceedance probability (return period) in any given year.

The flood risk changes continuously as each of its components changes. The hazard varies with measures taken in the catchment area that influence drainage conditions, and climate change may lead to drier or wetter conditions and/or to more extremes at both ends of the discharge frequency distribution. On the coast, the sea-level rises, the intensity and frequency of storms increases or decreases as the climate changes.

Rising values at risk and in particular their concentration in some areas certainly account for the highest share in the change of risk. Megacities with burgeoning populations and industrial development are making many regions ever riskier, in particular those on coasts and in flood plains. Also, the number and value of people's possessions are continuously rising.

Finally, vulnerability is increasing despite damage prevention efforts. In general, modern equipment and building materials are highly vulnerable. Almost any item contains electric or electronic components prone to damage when exposed to flood water or even humid (and/or salty) air. Drying them out and then using them again as in the past is no longer an option. The high 
concentration of people and dense infrastructure networks increase vulnerability too. Many objects depend on each other, and practically everything depends on electric power. Failure at one point in the system may have a domino effect and cause the whole system to fail. However, vulnerability can be-and often is-reduced by flood control measures.

Insurers and reinsurers have always needed to assess the probability of flood losses as a basis for their business operations. This requires risk modeling. There has been a shift from hazard modeling to risk modeling in both science and engineering in the past decade or so, as societies have recognized that providing protection for high values (e.g. a city) and low values (e.g. a crop field) for the same flood frequency does not make much sense economically. The goal should be to minimize the flood risk for a society, not to make it equal for everything and everyone.

\section{Flood Risk Reduction}

There are no defined boundaries that separate hazard, values at risk and vulnerability. "Hazard" is really a natural phenomenon that may become consequential if it assumes an extreme intensity. This component cannot be influenced by humanity except-in the long run-by mitigation of climate change.

In the context of a flood, this may be seen differently. As stated above, flood is a secondary hazard, the magnitude of which depends on several influencing parameters. We cannot influence rainfall intensity, but we can-to some extent at least-control the formation of a hazardous flood. Deforestation, the draining of wetlands, urban development and surface sealing, mono-cropping in agriculture, and river training often intensify the hazard; afforestation, river restoration and the establishment of retention areas may mitigate it. Hence, flood control systems consisting of levees, retention basins, reservoirs, diversion channels, etc. can also be quoted as ways of influencing the hazard, which is essentially the flood wave (or run-off).

Only if the hazard phenomenon exceeds a potentially damaging magnitude do the other two risk components become important. The most efficient way of controlling values at risk is to avoid settlement in hazardous locations. If a house is built not right by the river bank or the beach, but further away or inland on higher ground, a flood or storm surge cannot inundate it or tear it from its foundations. Raising buildings above a critical water level and avoiding placing any vulnerable items inside the building below that level can have a similar effect. Preventing people from moving to areas where they expect better living conditions is all very well in theory, but does not easily work in practice. Trying to convince people that they should leave their homes and move elsewhere is an even more futile exercise.

All other measures can be seen from the perspective of reducing vulnerability. Vulnerability reduction measures need to be permanent to be effective. Early warning enables people and goods to be evacuated and defense measures to be taken, but does not guarantee that there will be sufficient time to do so. Hence, levees, solid flood walls and high-lying entrances to basements and ground floors are better than mobile elements and plugs for doors and windows. However, the latter can be still very wise and cost-effective investments, as are waterproof cladding and making the lower parts of a building's interior water-resistant.

It is easy to understand the need for protection against a river flood, as the source of flooding-the river-is known. However, protection measures need to be well planned and designed, and are expensive. Providing protection against flood damage resulting from intense local precipitation is usually a much simpler affair-but often not considered necessary by owners. And yet a few inexpensive measures can prevent losses, at least from moderate flash flooding. In this context, short-term loss reduction measures can be more or less ruled out, because it is almost impossible to forecast a flash flood with sufficient accuracy and early enough to enable defensive measures to be taken.

The flood risk can be more effectively reduced by 
appropriate measures than the risk from any other natural hazard. Furthermore, flood prevention and flood control are highly cost-effective; every dollar spent on flood control eventually yields a much greater benefit in losses prevented. Many countries have improved their situation, but it was always a disaster that triggered the efforts: in the Netherlands and in Germany after the storm surges in 1953 and 1962 respectively, in the United States after the Great Mississippi flood in 1927, in China after the flood year of 1998, and so on. The risk is reduced for the moment-no question. However, whether it remains at a lower level depends on the developments on "the dry side of the levee".

An adverse effect of highly developed flood control and preparedness is the "feeling of security". People tend to ignore or eventually forget about the residual flood risk if nothing happens for a while, and increase the risk by accumulating assets. Alternatively, they may be lulled into a false sense of security, totally relying on flood protection and preventive measures. It is quite likely that systems that "always work" may not do so in the event of disaster.

Although technical flood protection is certainly the most important factor in preventing large disasters, we need to be aware that even the strongest, best-designed systems have a limited effect. The 2004 and 2011 tsunamis and hurricanes Katrina and Sandy showed that $100 \%$ safety is not possible. It is therefore crucial not to rely on a purely structural approach to the problem, but to include "soft" factors.

\section{The Partnership for Risk Reduction}

Risk (and loss) minimization calls for integrated action. The flood risk must be borne on several shoulders: the state, the populations and companies affected, and the financial sector, particularly the insurance industry. Only if they all cooperate in a finely balanced relationship and in a spirit of risk partnership can disaster prevention be truly effective.

\subsection{Public Authorities}

The primary task of the state or the government is to reduce the underlying risk for society as a whole. The government provides access to observation and early warning systems, builds levees, enacts laws that stipulate the framework for use of exposed areas and prepares emergency plans, including programs facilitating recovery (temporary housing, financial assistance, tax relief, etc.). In some countries, insurance programs are state-run. Much of the responsibility for flood protection lies with the public authorities.

\subsection{People and Companies}

Those immediately affected (individuals, companies and communities) have great potential for loss reduction. The crucial point is whether their risk awareness can be maintained. Even those who are conscious of the danger of flooding may, in time, forget about it, especially if nothing happens over a considerable period. People rely on protection systems, at the same time making their property more and more valuable by adding extra features that are often susceptible to water damage. Anyone proposing to erect residential or commercial properties must be informed and educated to ensure they are constructed in the appropriate manner. The owners need to check the level of exposed values, be ready to take action in an emergency and put in place financial precautions to deal with catastrophic losses, for example by purchasing insurance cover.

\subsection{Insurance Industry}

The true task of insurance companies is to provide compensation for financial losses that would have a substantial impact on insured or even constitute their ruin. Insurers carry the financial risk of events with such a low probability that they cannot be considered foreseeable. Insurance redistributes the burden borne by individuals among the entire community of insured. Ideally, that community is composed in such a way that 
all its members have some chance of being affected-even though the degrees of probability differ. Furthermore, insurers provide educational and public relations services, such as publishing brochures that draw attention to the hazards and explaining how to reduce the risk.

\subsection{Reinsurance Sector}

Insurance companies, like private individuals, try to avoid volatility in their payments. Natural perils insurance is highly volatile. Large single losses (from one event) can be reduced if part of the risk is transferred to the reinsurance sector, where business is often transacted worldwide. Catastrophic losses that occur in one country are distributed all over the world, thus relieving the burden on the local insurance market and possibly even preventing its collapse.

Insurance, and especially reinsurance, companies have to be ready to pay large amounts of money after major events. For example, Munich Re faced claims in the order of US\$2 bn both in 2001, following the World Trade Center attack, and in 2005, as a result of Hurricane Katrina. Despite the enormous sums involved, the company's existence was not under threat. However, volatility is expensive. Money for claims payments must be made available very quickly and cannot be placed in long-term, possibly more profitable, investments. With single-loss amounts increasing, the whole financial market-including banks and investors-became more and more involved in the coverage of risk [7].

All of the risk-reduction efforts cannot work if there is not an adequate level of risk awareness at all levels in a society, from the homeowners to the government. Awareness must be raised and maintained. Unfortunately, this is best achieved the hard way: by repeated occurrence of losses. No education campaign and no incentive is as effective as a flood event that confirms the hazard. Through the event the probability-linked term "risk" becomes "loss", i.e. the probability becomes certainty.

\section{Examples of Flood Risk Management}

Three extreme floods in 2011, the two river floods in Thailand and along the Mississippi in the United States, and the tsunami in Japan, as well as some recent storm surges (US Hurricanes Katrina in 2005 and Sandy in 2012, Typhoon Haiyan in the Philippines in 2013, Winterstorm Xaver in Germany in 2013), clearly showed how different the consequences can be depending on the degree of development of flood risk management.

\subsection{Chao Phraya (Thailand)}

The broad flat plain of the Chao Phraya River, Thailand's heartland, generates $40 \%$ of the country's gross national product. The 2011 flood was the worst Thailand had experienced in 50 years and, with overall losses of US\$ 43bn, it was globally the costliest inland flood of all time.

Over the past 30 years, Thailand has developed rapidly. With its burgeoning population (1980: 46.5 million, 2010: 68 million) and economic growth, there has been a proliferation of huge new settlements, particularly commercial and industrial parks, with assets valued in the tens of billions. The traffic and supply infrastructures have also significantly expanded, especially in Greater Bangkok. With the economy booming, the flood hazard became a side issue and was generally underestimated. Protection measures such as local levees were erected in a non-engineered manner and likely to fail in a crisis. At the same time, the flood hazard was increasing, as widespread tracts of land that had previously served as a buffer for flood waters were swallowed up by development.

When the flood came in 2011, it clearly went out of control. Many of the measures taken were based on trial and error rather than on strategic and prepared plans. Additionally, the large industrial value concentrations, which had been developed in a careless and negligent way in areas prone to flooding, were overwhelmed by the waters. The large industrial parks were the principal loss drivers. Seven such parks, with 
1,000 production halls in which almost half a million people worked were meter-deep in water. Massive damage was caused to property, production was halted, and supplies and deliveries were interrupted, sometimes for weeks on end, ultimately with global repercussions. In Thailand, risk management had been clearly neglected and a high price had to be paid.

\subsection{Mississippi (USA)}

In May/June of 2011, the Middle and Lower Mississippi in the United States experienced the highest flows since 1927. That earlier event had been the signal for continuing flood control efforts. In 1928, the Flood Control Act was passed and the MR\&T (Mississippi River and Tributaries) project launched. The USACE (U.S. Army Corps of Engineers) was given the task of implementing and maintaining these measures. Levees have been erected over a length of $3,500 \mathrm{~km}$ and the water is now detained by a large number of detention basins. To date, the MR\&T project has cost US\$14bn (in original values). The Mississippi River Commission has estimated that it has prevented losses in the amount of US\$ $612 \mathrm{bn}$, or 44 times the sum invested [8].

The system includes three emergency floodways on the Mississippi. To prevent high flood losses, USACE in 2011 breached a section of a levee near New Madrid and opened the two downstream spillways. While losses did occur in the deliberately flooded areas, those flood management measures kept the Mississippi discharge below a level that would have posed a major threat to the cities of Baton Rouge and New Orleans, as well as to numerous industrial plants along the river's lower reaches. The damage and losses averted in 2011 for the Mississippi flood amount to several tens of billions of dollars. The long-term risk management paid off.

\subsection{Tsunami 2011 (Japan)}

Japan is more aware of and prepared for natural hazards than any other country. The country had not only built huge tsunami protection structures, but also taken non-structural measures in the form of information, education and training/exercise programs concerning natural hazards. When, on 11 March 2011, a tsunami approached and hit the central Honshu coast, most coastal residents reacted quickly and properly, as they had been trained to do. They fled to locations they thought were high enough, such as the tops of five-storey buildings. The fact that some were washed away even from these heights was due to the enormous power and height of the tsunami. Although the tsunami walls were overrun by the wave in many places, they at least reduced the power of the water to some extent and gave people a few more minutes to flee.

Comments to the effect that the tsunami proved that "all the efforts undertaken in the past decades were in vain" were misplaced-and even irresponsible. If there had been no program of coastal protection and civil preparedness, the death toll of almost 16,000 would have been a great deal higher. The event was just too extreme for a disaster to be avoided. Even knowing that earlier tsunamis had reached similar heights, one could hardly have made coastal defenses stronger and higher. However, the urban development along such a high-hazard coast must be seen critically, despite Japan's shortage of suitable land. And the decision to build a nuclear plant like Fukushima Daiichi at a location like this is highly negligent and unforgivable. Japan's risk management in the past was largely comprehensive, but it vastly underestimated the occurrence probability of an event with extreme consequences, the nuclear accident.

\subsection{Typhoon Haiyan (Philippines)}

Typhoon Haiyan's storm surge (Philippines, 2013) hit the island of Leyte and Tacloban City in an unexpected and surprising way. The danger of such an event does not appear to have been considered by authorities and/or scientists, so that risk reduction efforts had not been considered either. Commentators, rather than blaming anyone, talked about an 
unavoidable "accident"/"natural disaster"/"worst possible scenario". Although some argued that the uprooting of mangrove forests to make way for shrimp farms in the absence of other sources of income meant that the surge was not weakened as much as it would otherwise have been, there was more or less a consensus that Tacloban could not have been protected against the disaster. Risk management could only have focused on preventing a high concentration of settlements close to the coastline-but who really could have enforced such a ban?

\subsection{Hurricanes Katrina and Sandy (United States)}

Hurricane Katrina's storm surge, which submerged New Orleans in 2005, and Sandy's in the New York area in 2012 were events close to a worst case. However, both storm surge scenarios had been described before and cannot therefore be called surprising. Despite good knowledge of the risk, no efforts were made to mitigate or prevent it. It was downplayed or ignored, or at least action was delayed. Both storms together cost more than US\$170bn. A small fraction of this sum invested in protective measures would have probably saved tens of billions of dollars in losses. Risk management must not stop at risk identification and assessment. Merely paying lip service to the findings is not acceptable-action needs to be taken without too much delay.

\subsection{Winter Storm Xaver (Hamburg/Germany)}

In December 2013, a winter storm (Xaver) produced a storm-surge water level in Hamburg that was the second highest (6.08 meters above mean sea level) in 100 years and $38 \mathrm{~cm}$ higher than during the disaster in 1962. Then, roughly one sixth of the city was under water; 318 people lost their lives and the loss totaled $€ 1.68 \mathrm{bn}$ (US\$ 2.3bn) at present-day (2014) values. Hamburg invested huge amounts in flood protection in the years and decades that followed $(€ 2.34 \mathrm{bn}=$ US\$ 3.2bn, 2014 values). Although storm surges in the city today reach greater levels than they did 50 years ago, the city has remained practically unscathed by flooding. A cost-benefit analysis using different scenarios indicated gains of between $€ 6 \mathrm{bn}$ (US\$ 8.2bn) and around $€ 20 \mathrm{bn}$ (US\$ 27.4bn) [9]. The gain is defined as the difference between losses prevented and money invested. The lower figure is based on the assumption that the losses incurred in the affected city area during each storm surge of at least 5.85 meters would be equal to the 1962 figure (minimum assumption). The higher figure takes into account the increase in concentration of asset values in the potentially flooded area, a more realistic view. Roughly $€ 6.7 \mathrm{bn}$ (US\$ 9.2bn) would have been attributable to storm Xaver alone. The efforts to reduce the flood risk by predominantly permanent and costly structural defense measures have been highly successful: the pay-off is of the order of $1,000 \%$.

\section{Conclusions}

We will not be able to eliminate the flood risk. We have to live with it-and manage it. Managing the flood risk means sharing it, refraining from exposing values to risk, erecting and reinforcing protection installations, responding appropriately as potential flood victims, and preparing for disaster financially, i.e. taking out insurance cover. Even if all of these things are done, flood losses cannot be completely prevented, but large disasters can be. Numerous examples have confirmed that protection pays off. Unfortunately, action often starts after a devastating event. Creating and maintaining high risk awareness at all levels of society plays an important role. Without the will of the members of a civil society to spend money, to contribute time and resources and to behave appropriately in flood-prone areas, the friction that slows down and often even prevents useful action remains too high.

\section{References}

[1] Beilharz, J., Rauch, B., and Wallner, C. 2014. "Insurance against Natural Catastrophes is Essential, Particularly in Developing and Emerging Economies." Munich Re 
Topics Geo Natural Catastrophes 2013 (1): 13-4.

[2] Kron, W. 2013. "Coasts-the High-risk Areas of the World." Natural Hazards 66 (3): 1363-82.

[3] Kron, W. 2012. "Severe floods in Australia, the USA and Thailand." Munich Re Topics Geo Natural Catastrophes 2011 (1): 26-31.

[4] UNISDR 2009. UNISDR Terminology on Disaster Risk Reduction. Geneva: United Nations International Strategy for Disaster Risk Reduction.

[5] IPCC 2012. Managing the Risks of Extreme Events and Disasters to Advance Climate Change Adaptation. A special Report of Working Groups I and II of the Intergovernmental Panel on Climate Change, IPCC/SREX/2012. Field, C. B., Barros, V., Stocker, T. F., Qin, D., Dokken, D. J., Ebi, K. L.,
Mastrandrea, M. D., Mach, K. J., Plattner, G. K., Allen, S. K., Tignor, M. and Midgley P. M. (eds.), Cambridge and New York: Cambridge University Press.

[6] Kron, W., 2005. "Flood Risk = Hazard · Values · Vulnerability." Water International 30 (1): 58-68.

[7] Kron, W. 2009. "Flood Insurance-from Clients to Global Financial Markets." Journal of Flood Risk Management 2009 (2): 69-75.

[8] Mississippi River Commission 2013. Executive Summary-389th and 390th Sessions. Vicksburg, MI.

[9] Kron, W., and Müller, O. 2014. "Benefits Far Outweigh the Costs." Munich Re Topics Schadenspiegel 2014 (1): 40-4. 